NASA Technical Memorandum 100117

\title{
Thermal Finite-Element Analysis of Space Shuttle Main Engine Turbine Blade
}

Ali Abdul-Aziz, Michael T. Tong, and Albert Kaufman

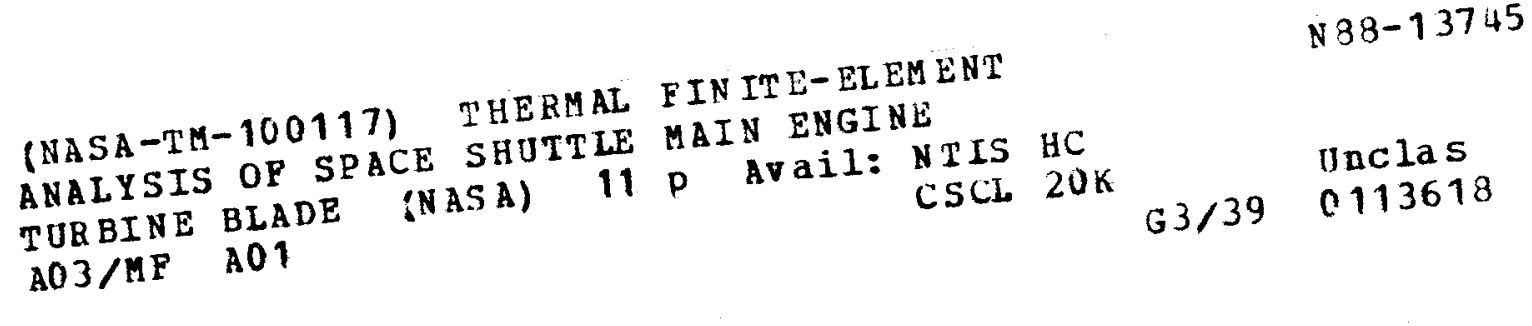

October 1987

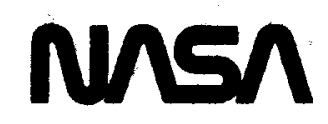




\title{
Thermal Finite-Element Analysis of Space Shuttle Main Engine Turbine Blade
}

\author{
Ali Abdul-Aziz and Michael T. Tong \\ Sverdrup Technology, Inc. \\ Lewis Research Center \\ Cleveland, Ohio \\ and
}

\begin{abstract}
Albert Kaufman
Lewis Research Center

Cleveland, Ohio
\end{abstract}

October 1987

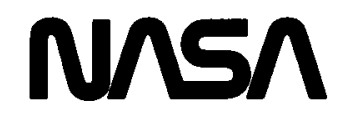

National Aeronautics and

Space Administration

Lewis Research Center

Cleveland, Ohio 44135 


\section{Summary}

Finite-element, transient heat transfer analyses were performed for the first-stage blades of the space shuttle main engine (SSME) high-pressure fuel turbopump. The analyses were based on test engine data provided by Rocketdyne. Heat transfer coefficients were predicted by performing a boundarylayer analysis at steady-state conditions with the STANS boundary-layer code. Two different peak-temperature overshoots were evaluated for the startup transient. Cutoff transient conditions were also analyzed. A reduced gas temperature profile based on actual thermocouple data was also considered. Transient heat transfer analyses were conducted with the MARC finite-element computer code.

\section{Introduction}

The purposes of this study were to calculate the thermal response in an SSME turbine blade for subsequent structural analysis and to gain greater understanding of blade damage modes, convective cooling effects, and the effects of changes in gas profile. The heat transfer analyses were performed by using a nonlinear, three-dimensional, finite-element analysis computer code. The calculated metal temperature distribution and history were then used for a nonlinear structural analysis of the blade with the same three-dimensional, finite-element analysis computer code.

Experimental measurements of gas temperature profiles in the SSME turbopumps are difficult to obtain because of the severe operating environment within the SSME. However, the operating temperatures of the turbine blade in rocket engine turbopumps are primarily a function of the hot gas flow and cooling. The temperature field is determined by the heat transfer from the hot gas to the blade. This heat transfer and its variations are determined from knowledge of the gas film coefficients. The temperature gradient through a blade is governed by such factors as blade geometry; location of shrouds, platforms, dampers, etc.; and the presence of coating material. Determining blade temperatures at the startup and cutoff of an engine cycle is difficult because of the complex nature of flow through an accelerating turbine. Thus, the timetemperature history profile at the startup transient, during steady state, and at cutoff was obtained through a combination of analytical and experimental results.
In the past, first-stage turbine blades in the high-pressure fuel turbopump (HPFTP) of the space shuttle main engine have undergone cracking near the blade shank region and at the airfoil leading edge adjacent to the platform. These cracks apparently were initiated during the first few mission cycles by severe thermal transients and were propagated by vibratory excitation. To achieve the necessary durability, these blades are currently being cast by using directional solidification. Single-crystal alloys are being considered for future SSME applications. Since the primary interest herein was in the airfoil region, the platform and shank were excluded from the finiteelement model to reduce the size of the problem and the related computing time. Also, knowledge of flow conditions at the platform, shank, and fir tree was lacking. The flow conditions at the shank and fir tree involve the mixing of hot main-stage gas with hydrogen coolant flowing up the disk. Details of this process are not known, and hardware evidence indicates that the thermal environment in these regions varies widely.

First-stage blades in modern, high-pressure gas turbines generally require film cooling. However, adding a layer of cooling air over the surface reduces turbine efficiency. To minimize this loss in efficiency, it is necessary to predict the external heat transfer coefficient during the airfoil design. Stepka (ref. 1) shows that the greatest improvement in the accuracy of metal temperature, and hence blade life prediction, can be achieved by improving the prediction of the external heat transfer coefficients. Therefore, accurate boundary-layer analysis and well-defined surface heat loads, aerodynamic losses, and boundary conditions will substantially improve the accuracy of heat transfer analyses. This report addresses the problems of calculating the thermal response of hightemperature gas-path components, such as turbopump blades in space power propulsion systems. The first-stage HPFTP blade in the SSME was selected for this study. A threedimensional, finite-element heat transfer analysis based on an engine test cycle was performed by using the MARC finiteelement code (ref. 2).

\section{Analytical Procedure}

A three-dimensional, finite-element model of the airfoil (fig. 1) was constructed of eight-node, solid, isoparametric elements. This model, consisting of 360 elements with 576 


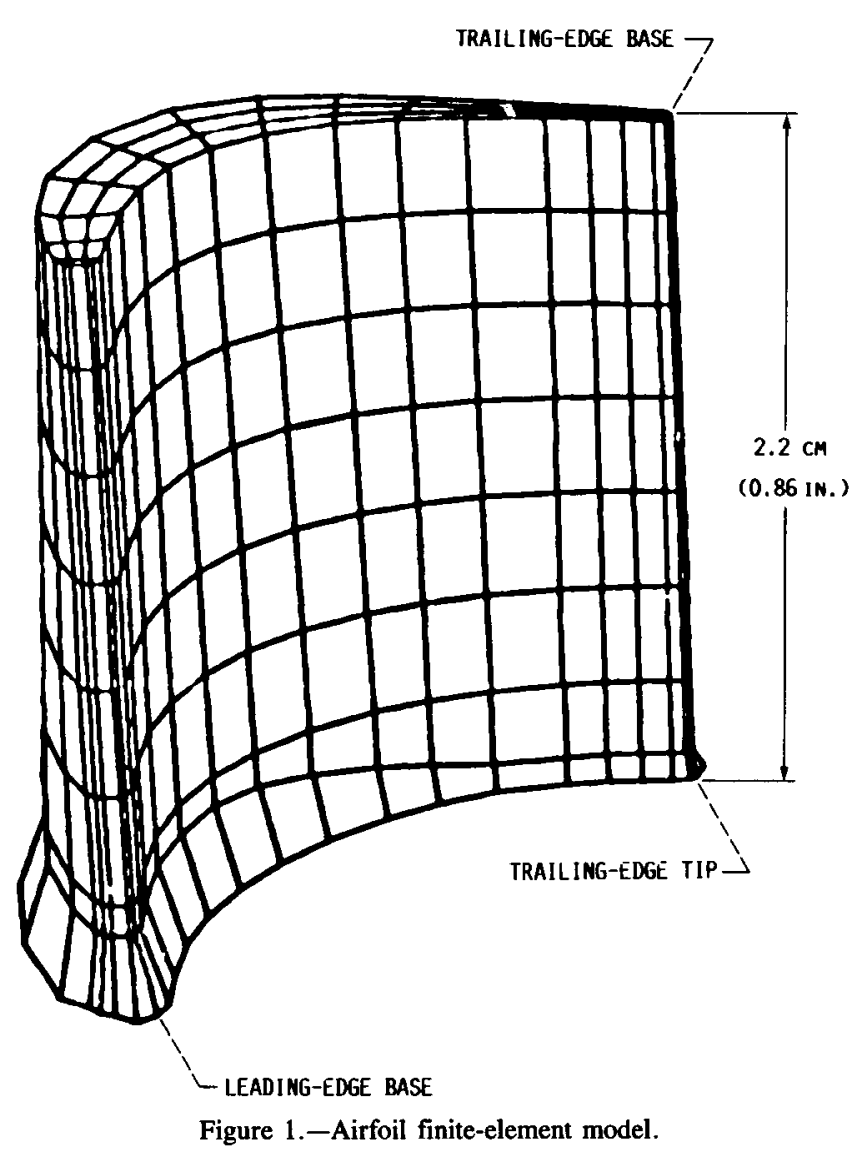

nodes, was a shortened version of a finite-element model created by Lockheed for a NASTRAN steady-state structural blade analysis (ref. 3). The main difference between the NASA Lewis and Lockheed models was that the blade base and most of the platform were omitted for the MARC heat transfer analysis in order to reduce the size of the problem as well as the computing cost for subsequent cyclic structural analysis. Analysis of the shank region was also hindered by lack of knowledge as to its thermal environment. The airfoil had a span length of $2.2 \mathrm{~cm}$ and a span-to-chord-width aspect ratio of approximately unity.

The finite-element formulation in MARC for the temperature at time $t$ can be expressed as

$$
T(x)=N(x) \bar{T}
$$

Temperature $T$ within the element is interpolated from the nodal values $\bar{T}$ of the element through the interpolation functions $N$ as given in equation (1). The governing equation of the heat transfer problem is

$$
C(T) \dot{T}+K(T) T=Q
$$

In equation (2), $C(T)$ and $K(T)$ are the temperature-dependent heat capacity and thermal conductivity matrices, respectively; $T$ is the nodal temperature vector; $\dot{T}$ is the time derivative of the temperature vector; and $Q$ is the heat flux vector.

The backward difference scheme selected for discretizing the time variable in equation (2) yields the following expression:

$$
\left[\frac{1}{\Delta t} C(T)+K(T)\right] T_{n}=Q_{n}+\frac{1}{\Delta t} C(T) T_{n-1}
$$

Equation (3) computes nodal temperatures for each time-step increment.

For evaluating temperature-dependent matrices, the temperatures at two previous steps provide a linear (extrapolated) temperature description over the desired interval.

$$
T(\tau)=T(t-\Delta t)=\frac{\tau}{\Delta t}[T(t-\Delta t)-T(t-2 \Delta t)]
$$

This temperature is then used to obtain average thermal properties of the material $f$ over the interval to be used in equation (3).

$$
f=\frac{1}{\Delta t} \int_{t-\Delta t}^{t} f[T(\tau)] d \tau
$$

During each iteration, the average properties are obtained from the results of the previous iteration.

A boundary-layer analysis was conducted to compute the gas film coefficients needed for the heat transfer computation. The first step in the analysis was to use the inviscid flow code MERIDL (refs. 4 and 5) to determine the flow characteristics at the plane midway between the two mean-camber lines of adjacent blades. The second step was to use the TSONIC code (ref. 6) to calculate each of the 11 streamlines blade to blade. By using the MERIDL and TSONIC codes, a quasi-threedimensional calculation was effected.

The thermal environment of the blade was determined by employing a two-equation Prandtl mixing-length turbulence model to conduct boundary-layer calculations throughout the flow. The modified STAN5 code (ref. 7) was used to compute the boundary-layer equations as well as the heat transfer coefficients. The theoretical basis of this computation is described in detail in reference 8. The blade was assumed to operate at the steady-state portion of a full power cycle. The mission cycle (fig. 2) consisted of a 4.5-sec transient from startup to steady state, a 23.5 -sec hold at steady state and a 4-sec transient cutoff or shutdown. Rocketdyne provided the gas conditions from engine test data. 


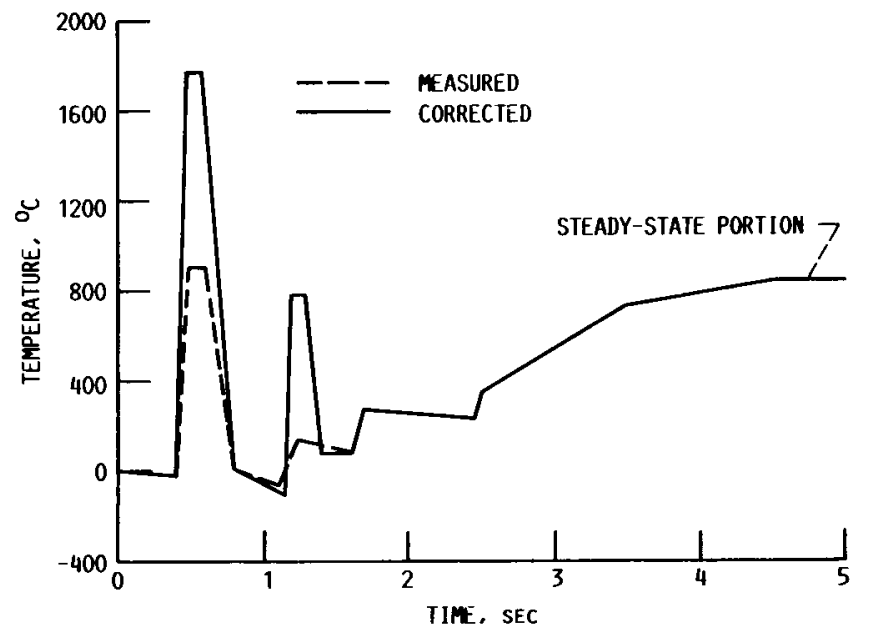

Figure 2.-Turbine inlet gas temperature for high-pressure fuel turbopump.

The finite-difference flow mesh used in the computation is shown in figure 3. The airfoil tip and hub cross-sectional geometries that were input into the flow codes are shown in figure 4. Rocketdyne supplied the inlet gas temperature and pressure distributions (table I). The STAN5 program uses air properties. To simulate the hydrogen/oxygen flow phenomenon, the Reynolds number was adjusted to maintain dynamic similarity. The leading edge of an airfoil poses a special problem for the STAN5 program in that a boundary-layer profile is required and therefore the calculations cannot start from a stagnation point. Gaugler (ref. 7) modified the STAN5 program by adding a subroutine to calculate the laminar boundary-layer profile on a cylinder at a specified surface distance from the stagnation line. However, when an attempt was made to get detailed heat transfer results in the cylindrical leading-edge region, the heat transfer coefficient predicted in that region did not agree with experimental correlation. Up to about $30^{\circ}$ from stagnation, the STAN5 results were strongly dependent on the starting point, $\phi_{0}$.

Therefore, to compute heat transfer coefficients for the leading edge, Gaugler recommends the use of the Martinelli et al. (ref. 9) correlation for local heat transfer on a cylinder in a laminar crossflow as given by

$$
N u_{d}=1.14 \operatorname{Re}_{d}^{0.5} \operatorname{Pr}^{0.4}\left(1.0-\left|\frac{\phi}{90}\right|^{3}\right) \quad \text { for } \phi<80^{\circ}
$$

where $N u_{d}$ is the Nusselt number based on the leading-edge diameter, $R e_{d}$ is the Reynolds number based on the freestream approach velocity and the leading-edge diameter, $\mathrm{Pr}$ is the fluid Prandtl number, and $\phi$ is the angle, in degrees, from the stagnation point.

Equation (6) is usually applicable only to laminar flow calculations for high-speed gas turbines. However, it was introduced into this analysis since angle effects were included. To account for transitional effects into turbulence, the average

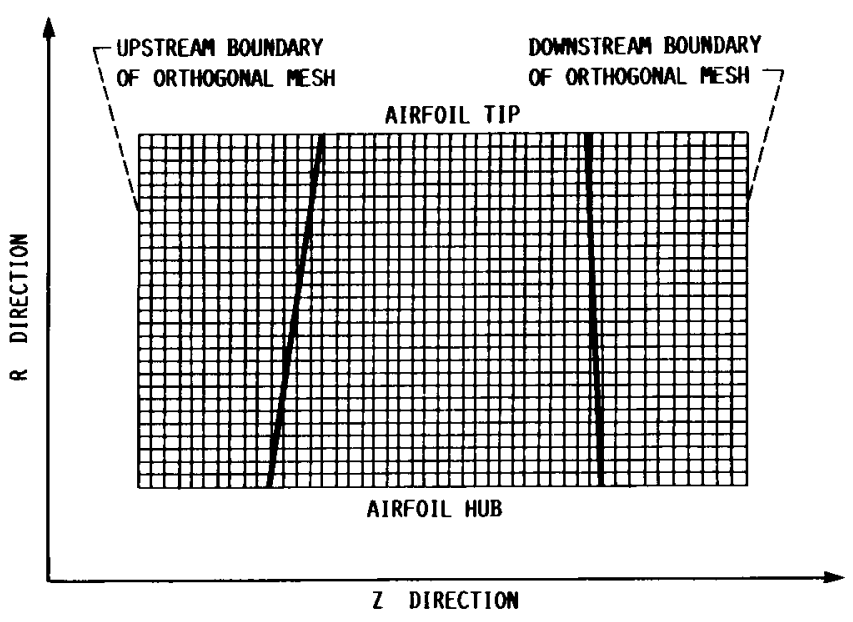

Figure 3.-Orthogonal mesh of HPFTP first-stage-blade airfoil.

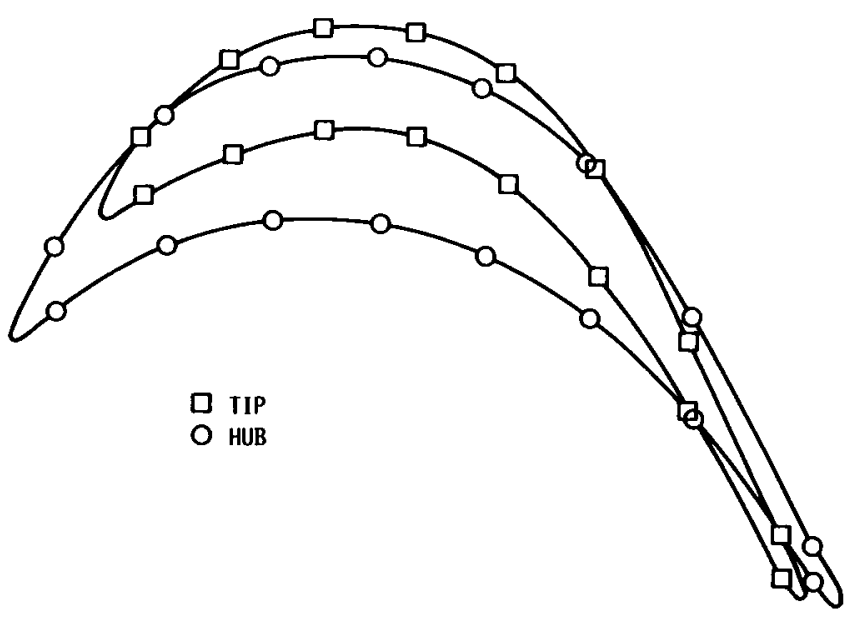

Figure 4.-Cross-sectional geometries of airfoil tip and hub sections.

heat transfer for a cylinder in crossflow was used. It is expressed by

$$
\begin{aligned}
\overline{N u}=0.3+0.62 \operatorname{Re}^{0.5} \operatorname{Pr}^{0.33} & {\left[1+\left(\frac{\operatorname{Re}}{282000}\right)^{0.625}\right]^{0.8} } \\
\times & {\left[1+\left(\frac{0.4}{P r}\right)^{0.67}\right]^{-0.25} }
\end{aligned}
$$

Equation (7) was recommended by Churchill and Bernstein (ref. 10). This correlation appears to provide a lower bound for $\operatorname{Re} \operatorname{Pr}>0.4$ and a reasonable approximation for all $\operatorname{Re}$ and $P r$. It differs from the prior correlating equation for forced convection to cylinders in that it provides a varying power for $R e$ and $P r$. The effective power of $R e$ in equation (7) depends on $\mathrm{Pr}$. Note that $\mathrm{Nu}$ is the average for the cylinder.

Calculations of the local values for the heat transfer coefficients at the leading-edge stagnation region were implemented 
TABLE I.-ROCKWELL INTERNATIONAL SSME HPFTP TURBINE GAS-PATH CONDITIONS

[Reference, 12-7-83 balance at full power level. Shaft speed, $36742 \mathrm{rpm}$; mean blade speed, $498 \mathrm{~m} / \mathrm{sec}$; oxygen/fuel mixture ratio, 1.0364 ; gas constant, 625.2 $\mathrm{J} / \mathrm{kg} \mathrm{K}$; viscosity, $2.852 \times 10^{-5} \mathrm{~Pa} \mathrm{sec}$; pressure ratio, 1.4491.]

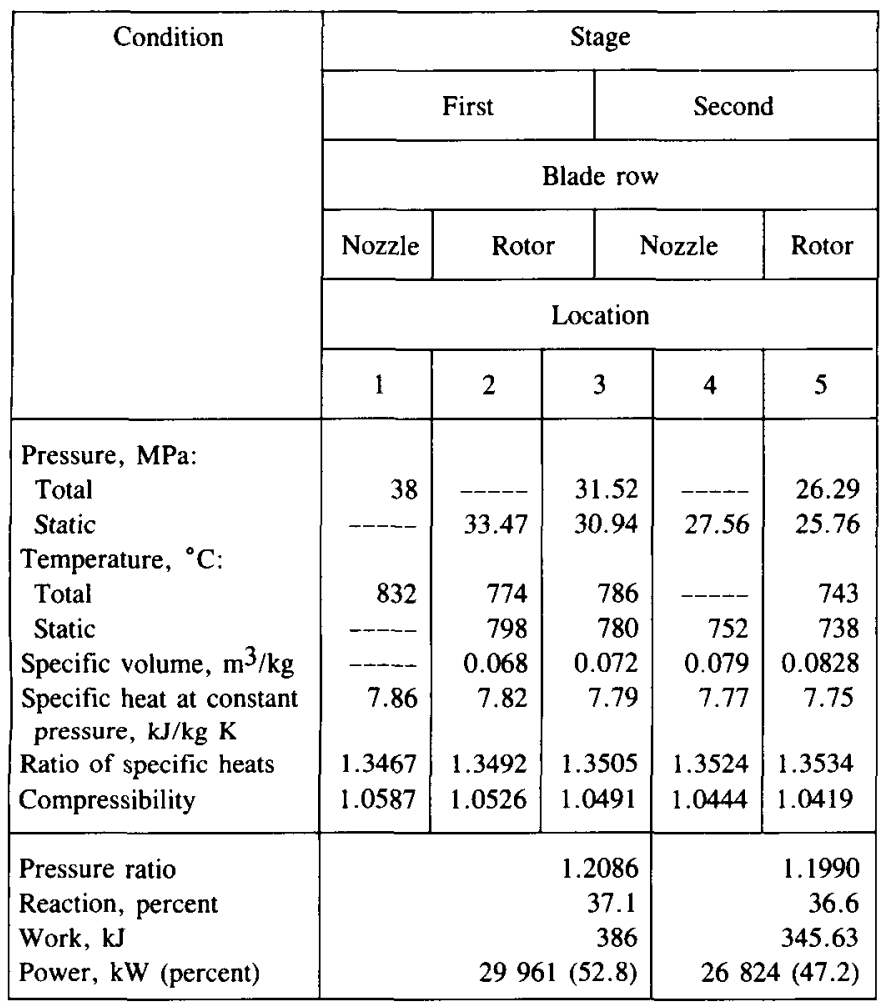

by multiplying the results obtained from equation (6) by the amplification term represented in equation (8). The multiplication combined the effects of angle, turbulence, and turbulent flow

$$
A=f^{*}\left[1+\left(\frac{\operatorname{Re}}{282000}\right)^{0.625}\right]^{0.8}
$$

where $f^{*}$ accounts for turbulence factor and the rest of equation (8) for turbulent flow. Nominal turbulence intensity $T u$ values for rocket engines are 10 percent or higher according to reference 11 . Because of the high-temperature excursions associated with the SSME environment, the $T u$ for the present work was chosen to be 10 percent. Therefore, on the basis of an $N u / R e^{0.5}$ equal to $1.1286 \mathrm{Pr}^{0.4}$ and $T u R e^{0.5}$ equal to 48 (at a $T u$ of 10 percent), a value of 1.6 was approximated for $f^{*}$ from figures 7 and 8 of reference 11 .

The calculated heat transfer coefficients along the airfoil surfaces from the leading to the trailing edge are shown in figure 5 . The heat transfer coefficients varied by no more than 20 percent at any axial location over most of the airfoil surface. Boundary-layer analysis showed higher heat transfer coefficients at the leading edge than at the trailing edge. Because of flow compression at the stagnation point, the heat transfer coefficients varied primarily from rapid changes in surface velocity.

To simplify the airfoil heat transfer analysis, the following assumptions were made: (1) radial hot-gas temperature profiles were very small, (2) circumferential variations in hot-gas temperature distribution were also small, and (3) the blade tip was insulated. Boundary conditions that reflected cooling by hydrogen fuel at the blade-to-disk attachment region were imposed by activating the MARC user subroutine FORCDT. The gas temperature was assumed to be constant over the airfoil surface at each time step. Boundary-layer predictions at full power level conditions were input into the thermal model by means of the MARC user subroutine FILM. Similarly, hot-gas temperature and Reynolds number histories were incorporated in the input. Figures 6 and 7 reflect 109 percent rated power level conditions.

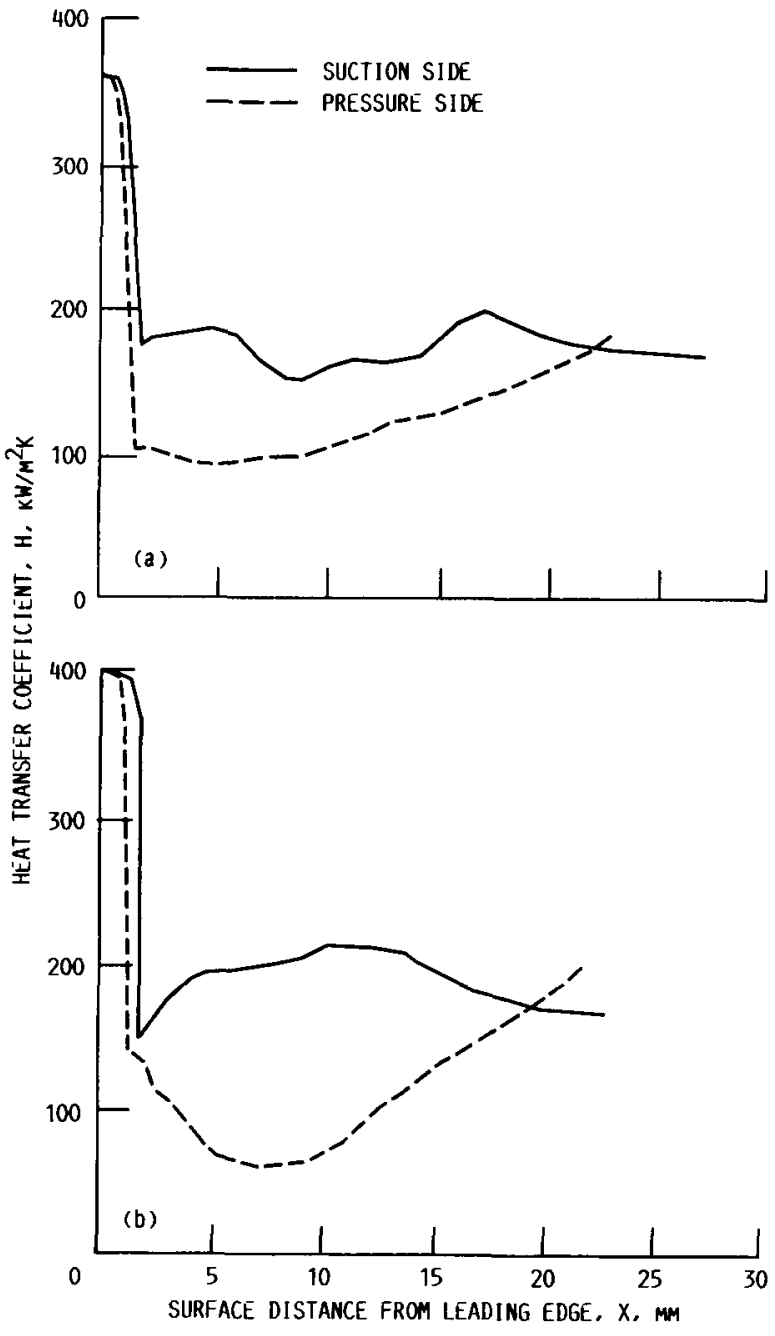

(a) At airfoil root.

(b) At airfoil tip.

Figure 5.-Distribution of heat transfer coefficients. 


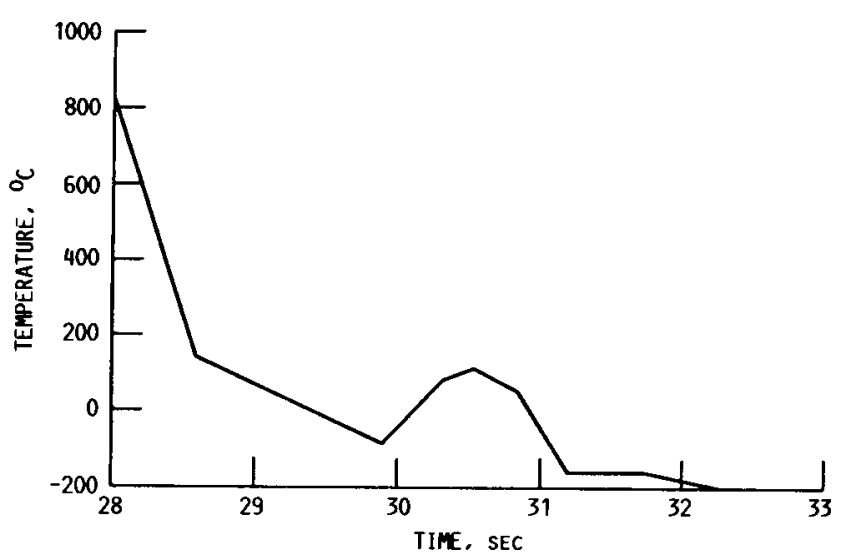

Figure 6.-Turbine inlet gas temperature (cutoff transient).

To obtain transient boundary conditions for both heated and cooled surfaces along the airfoil, these boundary-condition values were scaled according to the transient flow and temperature. In this scaling procedure, the flow was assumed to be turbulent. The steady-state heat transfer coefficients were adjusted by a factor that is the ratio of the Reynolds number over the steady-state Reynolds number. The Reynolds number ratio was raised to the power of 0.8 , a value assumed on the basis that correlations for heat transfer coefficients along a flat plate (which is the basis of this analysis) indicate that the heat transfer coefficient is proportional to the power of 0.8 for turbulent flow. In designing film-cooled gas turbine blades, this procedure has been found to be appropriate and yields satisfactory results.

Two different peak-temperature spikes, or overshoots, were evaluated for the startup transient. (These peak transients were based on data that Rocketdyne supplied for the existing SSME. The blades were cast from directionally solidified MAR-M 246 alloy. Temperature-dependent properties for this alloy were provided primarily by Rocketdyne.) The first spike was caused by the liquid-oxygen-rich mixture that occurred when the sudden increase in fuel preburner chamber pressure at ignition reduced the fuel flow. The second spike was caused by fuel oscillation, which is a cyclic phenomenon observed in the SSME. This oscillation reduced the fuel flow to the fuel preburner at about $1.3 \mathrm{sec}$. As the engine pressure increased, the oscillation vanished and the engine reached the main-stage operation. The notable feature of the total temperature profile for the maximum temperature spike condition (fig. 2) is the temperature excursion to $1800{ }^{\circ} \mathrm{C}$ at $0.6 \mathrm{sec}$. Because the thermocouple lagged in its response to a fast-changing transient gas temperature, this profile is a result of corrected thermocouple measurements and not the actual data readings. The correction brought the gas temperature up to $1800{ }^{\circ} \mathrm{C}$. A reduced temperature profile was also evaluated in which the same spike was limited to $900{ }^{\circ} \mathrm{C}$.

In this analysis, the automatic time-stepping scheme in MARC was used. It was based on a maximum temperature change per increment of $10 \mathrm{deg} C$. The program adjusts the

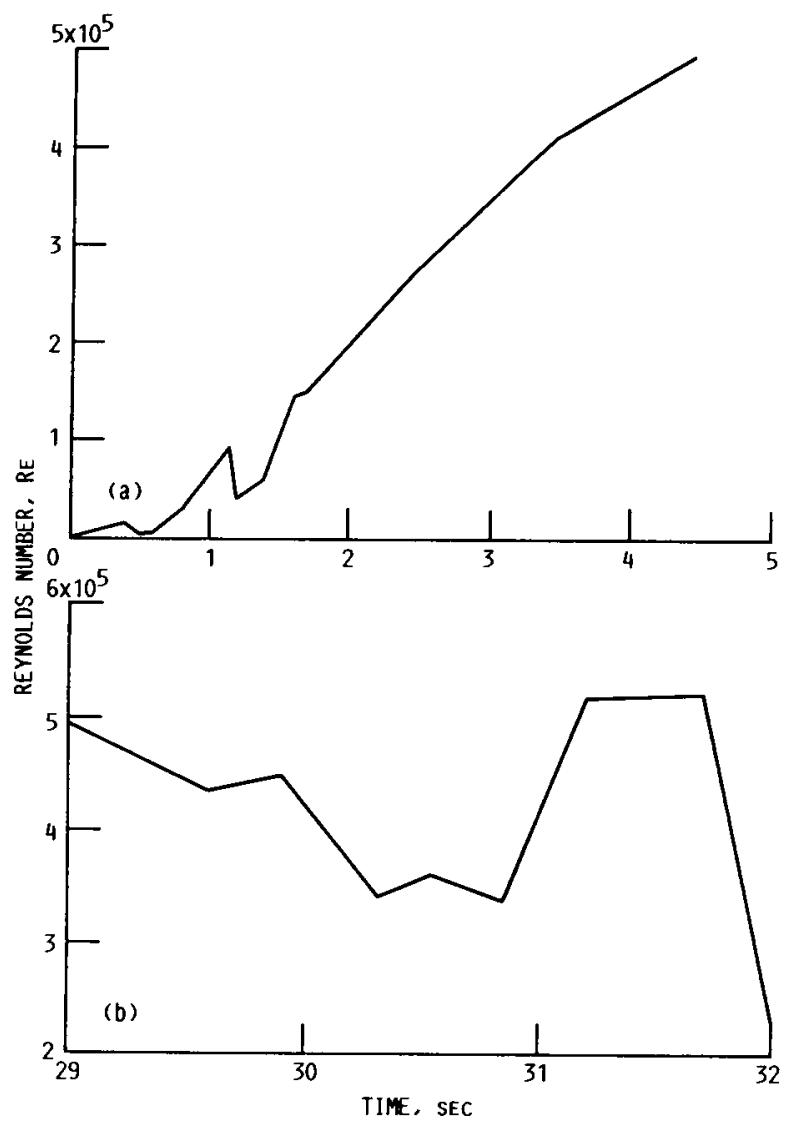

(a) At startup transient.

(b) At cutoff transient.

Figure 7.-Reynolds number.

time steps to conform to this criterion according to the scheme defined in volume $F$ of the MARC user manual (ref. 2). Tolerances are placed on the maximum temperature change before the program recalculates nonlinear effects and on the maximum temperature variation between the temperature used to evaluate properties and the resulting solution. The automatic time stepping resulted in 180 increments, and it took $755 \mathrm{sec}$ of central processing unit time to run the problem on the Lewis CRAY XMP computer.

\section{Discussion of Analytical Results}

Transient metal temperatures were obtained for the two startup spikes previously defined. The transient metal temperature responses at the hot-spot locations (the leadingedge base, the trailing-edge base, and the trailing-edge tip (fig. 1)) are plotted in figure 8. Figure 9 shows the response of the same hot-spot locations for the reduced temperature spike.

At $0.6 \mathrm{sec}$ after startup (fig. 10(a)), when the first ignition spike evaluated in the analysis occurred, the temperature gradient was essentially chordwise. This gradient tended to decrease until it reached the leading edge, where a significant 


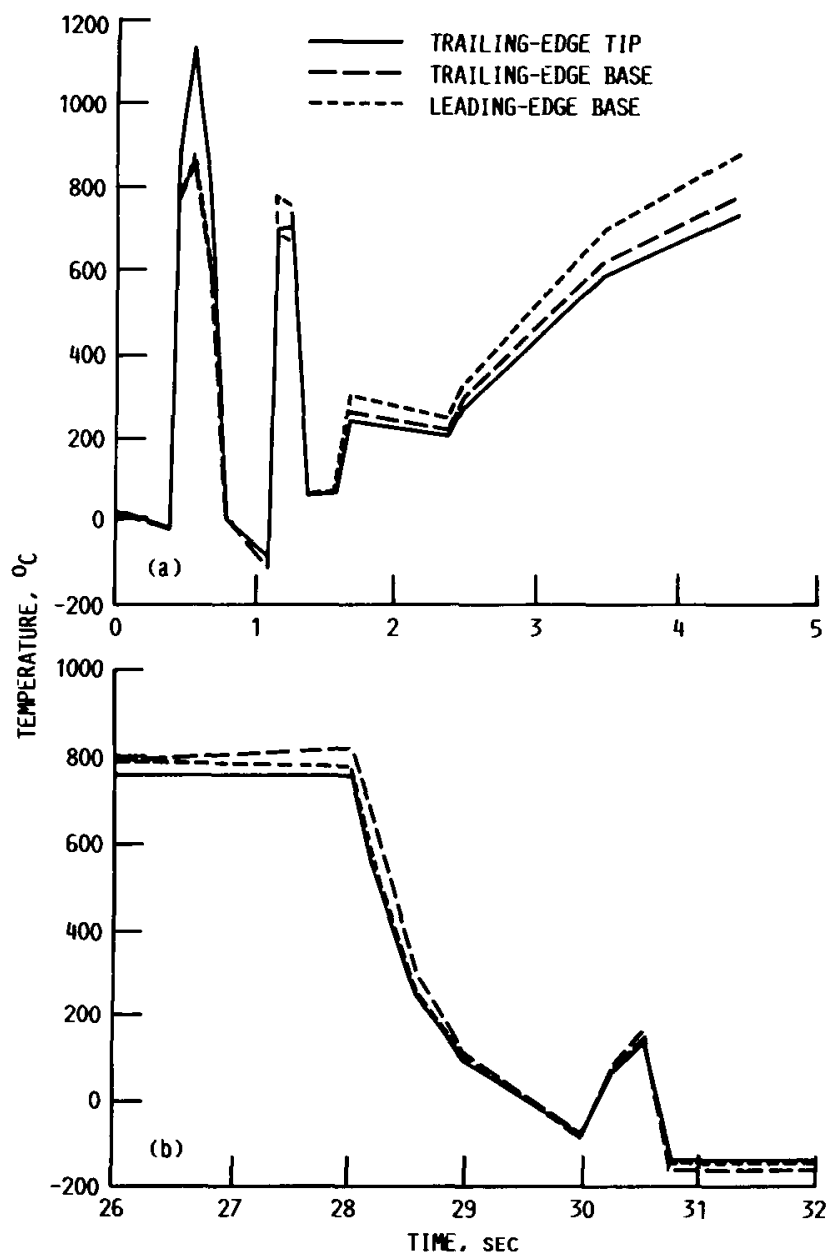

(a) At startup (corrected gas temperature profile).

(b) At cutoff.

Figure 8.-Airfoil transient temperature.

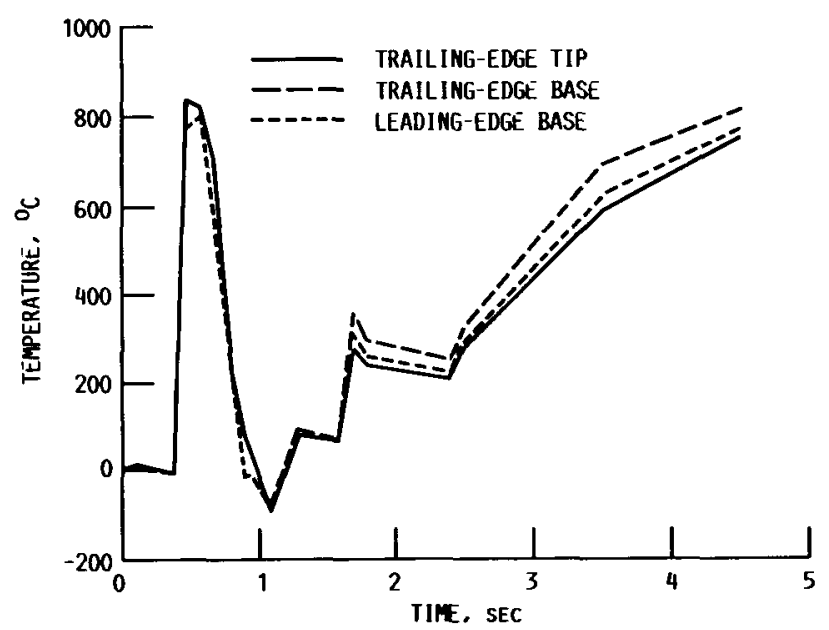

Figure 9.-Airfoil transient temperature at startup (uncorrected gas temperature profile). rise was observed. During this temperature spike, the highest temperatures occurred at the trailing edge, particularly near the tip, where the airfoil was thinnest.

At the second ignition spike evaluated, $1.3 \mathrm{sec}$ after startup (fig. 10(b)), the temperature gradient was spanwise, with the maximum temperature occurring at the leading edge near the airfoil base. This was expected because the high flow velocity yielded high heat transfer coefficients in this region. In addition, the large leading-edge offset caused a large gradient between the leading edge and the midspan surface. The temperature at the leading-edge base was approximately $667^{\circ} \mathrm{C}$; during the first ignition spike, the temperature was approximately $870^{\circ} \mathrm{C}$. The trailing-edge region experienced much lower temperatures than it did during the first ignition spike. At $4.5 \mathrm{sec}$ after startup (fig. 10(c)), a steady-state situation, or cruise, was encountered. Again, the hot-spot locations were at the leading and trailing edges at the airfoil base; the remaining surface experienced a relatively uniform temperature distribution. A gradient of about $100 \mathrm{deg} C$ existed at the trailing edge between the base and the midspan. This gradient was due to cold hydrogen gas cooling the blade root region. Also, the surface temperatures at the edges reacted nearly identically and were closely coupled with the transient gas temperature. This was expected because the high gas-path pressures resulted in extremely high heat transfer coefficients at the leading and trailing edges. The advantages of controlling the gas temperature spike, or overshoot, were reflected in a reduced leading-edge temperature at the 1.3-sec mark (fig. 9). The leading-edge temperature was reduced by a substantial 100 to $600 \mathrm{deg} C$, and the difference between the leading edge and the midspan surface was reduced from 200 to $112 \mathrm{deg} C$.

At cutoff conditions, the heat transfer results demonstrated that the maximum temperature was always at the leading-edge base (fig. 10(b)). The trailing edge was a secondary hightemperature region. The temperatures would have been much lower at the airfoil-shank junction if the temperature effects of the platform and the shank were not simulated by boundary conditions. Adding the platform would increase the heat dissipation by conduction through the platform surface.

Another factor unaccounted for in the scaling procedure was the effect of boundary-layer history, or the blade heat capacitance in response to gas temperature. When gas temperature increases abruptly, the boundary layer cannot heat as rapidly as the main-stream gas; consequently, the boundary layer shields the blade surface from the full effect of increased gas temperature. To examine the magnitude of boundary-layer history effects, a boundary-layer analysis should be conducted for the peak of the first ignition spike. Lower temperatures than those presented would be expected. Because there was insufficient information to permit a boundary-layer analysis at that time, an effort is now under way to collect the information needed to conduct transient heat transfer finiteelement analyses for a complete blade model, including the platform and shank regions. 

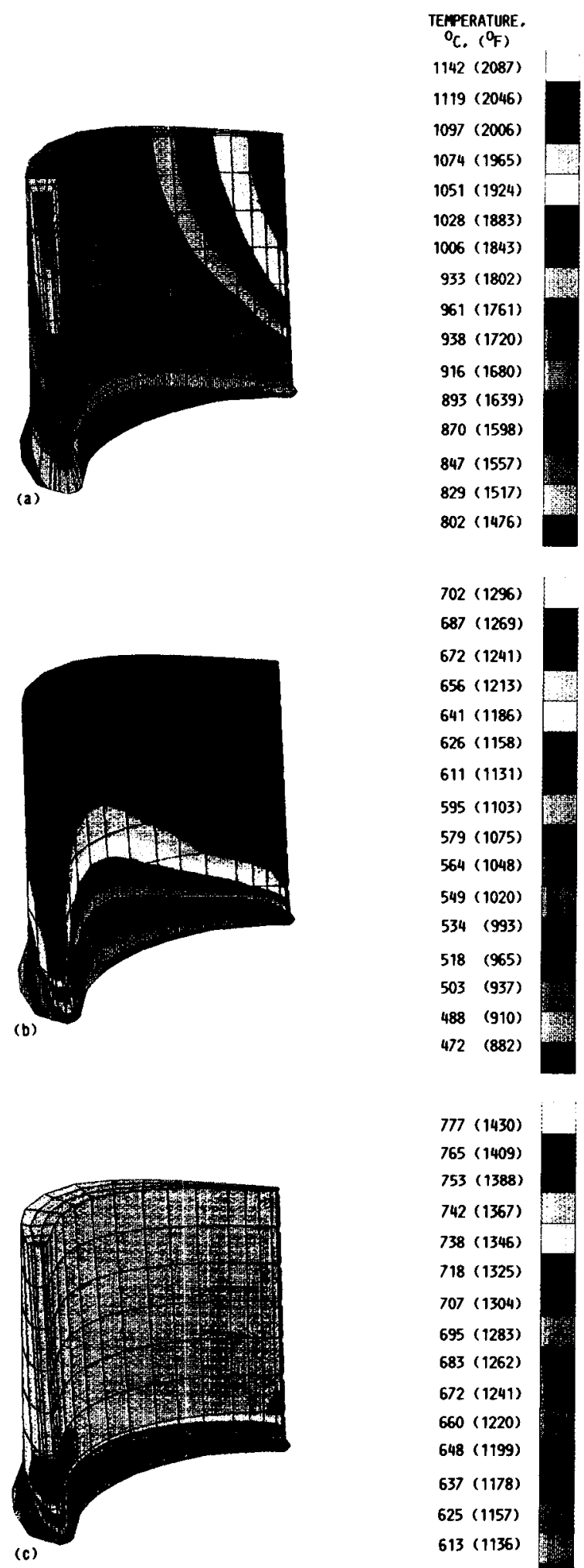

(a) At maximum spike (0.6 sec after startup).

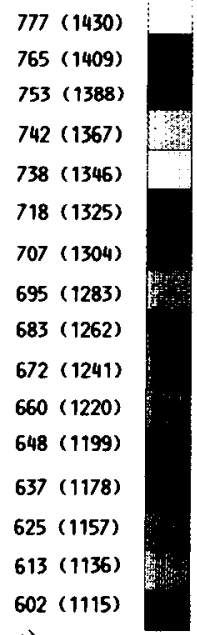

(b) At second spike (1.3 sec after startup).

(c) During cruise.

Figure 10.-Airfoil temperature distribution.

\section{ORJGINAL PAGE \\ COLOR PHOTOGRAPH \\ Summary of Results}

A three-dimensional, finite-element heat transfer analysis was conducted on the first-stage blades of the high-pressure fuel turbopump for the space shuttle main engine by using the MARC finite-element code. The modified STAN5 code was used to run a boundary-layer analysis that predicted the convective heat transfer coefficients. Predicted high-temperature locations on the blade airfoil were evaluated for a corrected gas temperature profile and compared with a reduced or actual thermocouple readout. All transient results presented were obtained by scaling steady-state heat transfer coefficients on the basis of transient flow and temperature. These results will be used as thermal input for the proposed structural analyses. The following general conclusions were drawn:

1. The thermal response predicted from the finite-element analysis showed that the leading- and trailing-edge bases of the airfoil are the hottest locations. This was expected because high heat transfer coefficients were present in these regions, and hardware evidence from mission flights as well as experiments has verified these results.

2. The use of the uncorrected, rather than the corrected, gas temperature profile resulted in a 14 percent decrease in the airfoil metal temperature at the leading edge as well as a 50 percent decrease between the midspan surface and the leading-edge base.

3. Temperature distributions showed a chordwise variation at the first ignition spike and a spanwise variation thereafter into the cycle. A uniform temperature distribution was dominant at most of the airfoil surface during cruise except near the base, where a mixture of cold and hot gas was present. The coldest spot was always at the airfoil base because the boundary conditions there were cooler.

\section{References}

1. Stepka, F.S.: Uncertainties in Predicting Turbine Blade Metal Temperatures. ASME Paper 80-HT-23, 1980.

2. MARC General Purpose Finite Element Analysis Program, Vol. A: User Information Manual; Vol. B: MARC Element Library; Vol. F: Theoretical Manual. MARC Analysis Research Corporation, Palo Alto, CA, 1980.

3. Hammett, J.C., et al.: Space Shuttle Main Engine Powerhead Structural Modeling, Stress and Fatigue Life Analysis. Vol. 1, (LMSC-HRECTR-D867333-1, Lockheed Missiles \& Space Co.; NASA Contract NAS8-34978), NASA CR-170999, 1983.

4. Katsanis, T.; and McNally, W.D.: Revised FORTRAN Program for Calculating Velocities and Streamlines on the Hub-Shroud Midchannel Stream Surface of an Axial-, Radial-, or Mixed-Flow Turbomachine or Annular Duct. Vol. I-User's Manual. NASA TN D-8430, 1977.

5. Katsanis, T.; and McNally, W.D.: Revised FORTRAN Program for Calculating Velocities and Streamlines on the Hub-Shroud Midchannel Stream Surface of an Axial-, Radial-, or Mixed-Flow Turbomachine or Annular Duct. Vol. II-Programmer's Manual. NASA TN D-8431, 1977. 
6. Katsanis, T.: FORTRAN Program for Calculating Transonic Velocities and Streamlines on a Blade-to-Blade Stream Surface of a Turbomachine. NASA TN D-5427, 1969.

7. Gaugler, R.E.: Some Modifications to, and Operational Experiences With, the Two-Dimensional, Finite-Difference, Boundary-Layer Code, STAN5. ASME Paper 81-GT-89, Mar. 1981. (NASA TM-81631.)

8. Crawford, M.E.; and Kays, W.M.: STAN5: A Program for Numerical Computation of Two-Dimensional Internal and External Boundary Layer Flows. NASA CR-2742. 1976
9. Martinelli, R.C., et al.: An Investigation of Aircraft Heaters, VIII-A Simplified Method for the Calculation of the Unit Thermal Conductance Over Wings. NACA Wartime Report W-14, Mar. 1943.

10. Churchill, S.W.; and Bernstein, M.: A Correlating Equation for Forced Convection From Gases and Liquids to a Circular Cylinder in Crossflow. J. Heat Trans., vol. 99, no. 2, May 1977, pp. 300-306.

11. O'Brien, J.E.; and Van Fossen, G.J., Jr.: The Influence of Jet-Grid Turbulence on Heat Transfer From the Stagnation Region of a Cylinder in Crossflow. ASME Paper 85-HT-58, Aug. 1985. (NASA TM-87011.) 


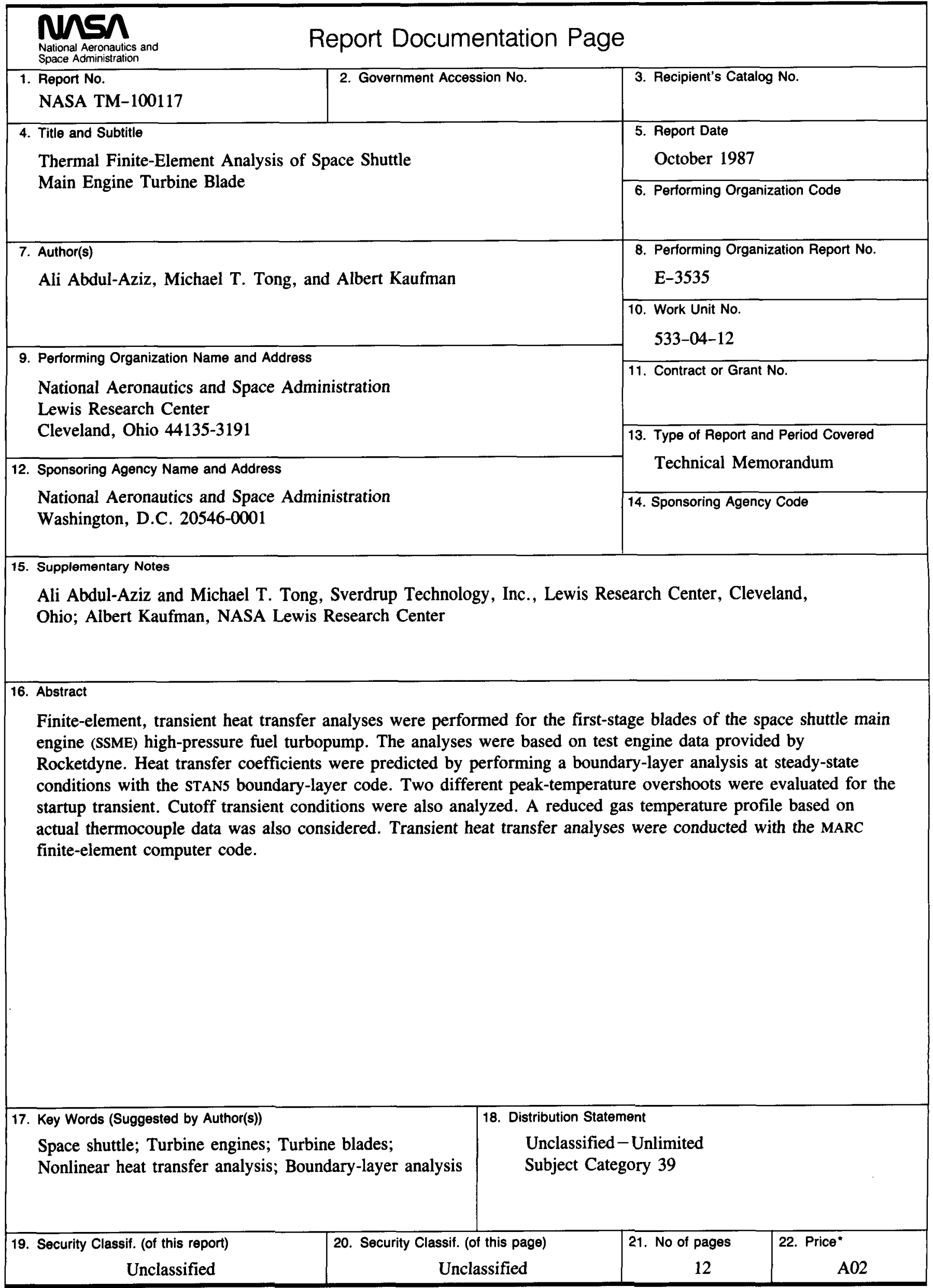

NASA FORM 1626 OCT $86 \quad$ *For sale by the National Technical Information Service, Springfield, Virginia 22161 